\title{
Política de Formação de Professores: responsabilidades dos programas de pós- graduação em Administração
}

\author{
Policies of Professor's Formation: resposibilities of graduate programs in Business \\ Administration \\ Manolita Correia Lima ${ }^{1}$, Danilo Martins Torini ${ }^{1}$, Ivor Prolo ${ }^{* 1}$, Claudia Cristiane dos Santos Silva ${ }^{1}$ \\ ${ }^{1}$ Escola Superior de Propaganda e Marketing (ESPM), São Paulo, Brasil.
}

\begin{tabular}{|c|c|}
\hline I NFO A R T IGO & RES U MO \\
\hline $\begin{array}{l}\text { Palavras-chave: } \\
\text { Formação de Professores, } \\
\text { Educação Superior, } \\
\text { Programas de Pós-Graduação } \\
\text { em Administração, } \\
\text { Didática, } \\
\text { Estágio de Docência. }\end{array}$ & $\begin{array}{l}\text { A política de formação de professores universitários no país pode estar refletida na } \\
\text { atuação prioritária dos Programas de Pós-Graduação (PPG), em especial os cursos de } \\
\text { formação de administradores. Neste aspecto, este artigo tem por objetivo compreender } \\
\text { a política de formação de professores nos cursos de pós-graduação - foco na } \\
\text { administração. Essa investigação assume características qualitativo-interpretativas e } \\
\text { se fundamenta em materiais resultantes de um levantamento documental. Entre os } \\
\text { principais resultados, questiona-se o diálogo entre pesquisa e ensino e a oferta de } \\
\text { disciplinas voltadas para a formação didática e pedagógica de mestrandos e } \\
\text { doutorandos. Entre as principais conclusões, é possível afirmar que a política } \\
\text { norteadora de formação do professor universitário no Brasil, em especial nos cursos } \\
\text { de administração, fortalece o processo de (des)profissionalização docente. }\end{array}$ \\
\hline ARTICLE INFO & ABSTRACT \\
\hline $\begin{array}{l}\text { Keywords: } \\
\text { Professor's Formation, } \\
\text { Higher Education, } \\
\text { Graduate Programs in } \\
\text { Business Administration, } \\
\text { Didactics, } \\
\text { Professor Internship. }\end{array}$ & $\begin{array}{l}\text { The policy of training university professors in the country can be reflected in the } \\
\text { priority action of the Postgraduate Programs (PPG), especially the formation courses } \\
\text { for administrators. In this aspect, this article purpose to understand the policy of } \\
\text { professor education in postgraduate courses in business administration. This research } \\
\text { admits qualitative-interpretative characteristics and basement on materials resulting } \\
\text { from a documentary survey. Among the main results, we question the dialogue } \\
\text { between research and teaching and the offer of disciplines focused on didactic and } \\
\text { pedagogical formation of masters and doctoral students. Among the main conclusions, } \\
\text { it is possible to affirm that the orientation policy of the university professor in Brazil, } \\
\text { especially in the administration courses, strengthens the process of professor's } \\
\text { (de)professionalization. }\end{array}$ \\
\hline
\end{tabular}

\section{Introdução}

Contemporaneamente prolifera a veiculação de um discurso que explicita a valorização da ideia de trabalho em detrimento da noção de profissão (LIMA; SILVA, 2011). Entretanto, em tempo algum, viram-se tantos acadêmicos, profissionais liberais, dirigentes políticos e empresariais, das mais diversas cores e filiações, debruçarem-se na discussão de temas voltados para a Educação, particularmente para o fortalecimento da profissionalização dos professores.

Paradoxalmente, sobretudo de 1990 em diante, o mercado editorial publica textos cujo conteúdo expressa o mal-estar que se instala no ambiente educacional, em todos os níveis de formação. Alguns títulos são particularmente contundentes, mas todos eles têm em comum a formulação de diagnósticos para a crise que ganha densidade na Educação e recorrentemente expõe os professores a flagrante desvalorização social (LIMA; SILVA, 2014). Nesse sentido, grande parte da literatura que coloca em dúvida a educação formal, a importância das instituições e dos sujeitos envolvidos no processo educacional prolifera entre representantes do meio acadêmico

\footnotetext{
* Principal contato para correspondência.

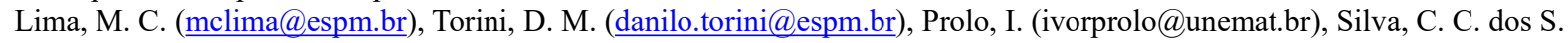
(claudia@espm.br).
}

DOI: dx.doi.org/10.21714/1679-18272019v17Ed.p32-45 
(LIMA; SILVA, 2014).

A universidade brasileira não está ausente deste debate, três coletâneas revelam que o mal-estar também está presente nos trópicos: em 1999, inspirado pelas reflexões de Readings e em resposta à política de educação superior do Governo Fernando Henrique Cardoso, Trindade organiza a coletânea Universidade em ruínas, na república dos professores; em 2000, Dias Sobrinho e Ristoff publicaram a coletânea A universidade desconstruída, avaliação institucional e resistência; em 2001, Gentili também recorre a uma metáfora ao organizar Universidades na penumbra: neoliberalismo e reestruturação universitária.

Em 2003, o então ministro da educação (Cristovam Buarque) divulga o texto Universidade numa encruzilhada e inaugura o seminário Universidade: por que e como reformar? na expectativa de promover um debate propositivo acerca dos rumos da universidade no País. Nessa ocasião, intelectuais renomados expuseram as suas reflexões sobre a crise da universidade e apontaram horizontes possíveis para a Instituição. Curiosamente, os temas debatidos não aprofundaram aspectos atinentes à formação do Professor para o magistério superior, às atividades acadêmicas que estão sob a sua responsabilidade, tampouco à carreira docente. Nos respectivos discursos, desconsideram o fato de o Professor não ser um coadjuvante nas atividades estruturantes de uma universidade na medida em que está à frente das atividades que combinam ensino, pesquisa, extensão e gestão acadêmica. Levando em conta o contexto aqui descrito, caberia questionar qual tem sido a política norteadora da formação do Professor universitário no País? Em que medida é possível afirmar que ela fortalece o processo de (des)profissionalização docente? Qual vem sendo a contribuição dos Programas de Pós-Graduação (PPG) na formação do Professor dos cursos de Administração? Neste sentido, o objetivo deste artigo é compreender a política de formação de professores nos cursos de pós-graduação, com foco nos cursos de administração.

Para discutir estas questões, os autores se apoiarão em um levantamento documental. A arquitetura do texto está dividida em oito seções, além da Introdução. Inicialmente há uma descrição dos recursos metodológicos explorados, em seguida o material coletado fundamenta reflexões sobre a política de formação de professores para o Ensino Superior; a capacidade dos Programas de Pós-Graduação em Administração (PPGA) influírem sobre a qualidade do ensino de Administração; a importância do diálogo entre pesquisa e ensino; as condições da oferta de disciplinas voltadas para a formação didática e pedagógica de mestrandos e doutorandos.

\section{Descrição dos Recursos Metodológicos Explorados}

A investigação assume características qualitativo-interpretativas (PRASAD, 2005; STAKE, 2016), combinando recursos típicos das pesquisas documental. A investigação realizada se apoiou em recursos típicos da pesquisa documental. Os dados foram extraídos da Constituição do Brasil (1988); da Resolução ${ }^{\circ}$. 12/83 do Conselho Federal de Educação (CFE); da Lei de Diretrizes e Bases da Educação Nacional (Lei n. 9394, 1996); da Circular no. 028/99/PR/CAPES; do Plano Nacional de Educação 2014-2024 (Lei n. 13.005, 2014); do relatório sobre o Exame Nacional de Desempenho de Estudantes (MEC/INEP, 2014); do Caderno de Indicadores da CAPES (20072012), da Plataforma Sucupira (2014) e do Censo da Educação Superior (CENSUP) de 2013.

Considerando que objetivo da investigação reside em reunir materiais que fundamentem discussões acerca da contribuição dos PPGA para a formação do Professor, a pesquisa documental extraiu dados sobre atividades curriculares que estivessem orientadas para esse propósito. Assim sendo, o corpus da pesquisa foi formado por 35 PPGA e dois cursos de doutorado (Universidade Metodista de Piracicaba e PUC-RS). O protocolo de coleta previu o registro de dados sobre a oferta de disciplinas relacionadas à formação científica e pedagógica dos estudantes, conforme descrito na Tabela 1.

Tabela 1: Protocolo da Coleta de Dados.

IES PPG / Ano de $\begin{gathered}\text { Campo de conhecimento } \\ \text { Criação }\end{gathered}$
$\begin{gathered}\text { de interesse para a } \\ \text { pesquisa }\end{gathered}$


Superior; Didática do Ensino Superior; Didática de Ensino; Didática; Ensino e Aprendizagem; Estratégias de Ensino; Capacitação Docente; Capacitação e Prática Docente; Seminário de Docência; Estágio de Docência; Monitoria; Pedagogia Universitária; Estrutura e Organização da Educação Superior no Brasil.

Fonte: Elaborado pelos autores.

O levantamento de dados foi realizado entre Fevereiro/Março de 2017 e teve como recorte temporal o período de 2007 a 2014. Esse recorte permitiu levar-se em consideração possíveis influências do Pró-Administração (Edital 28/11/2008) sobre a formação didático pedagógica dos mestrandos e doutorandos.

O processo de interpretação dos dados ocorreu com base na literatura que trata a formação de professores, considerando desde autores clássicos a contemporâneos até que se chegar a uma contextualização da política de formação de professores no âmbito macro (nacional brasileiro) ao âmbito micro (os cursos de pós-graduação em administração). Por fim, a reflexão, por meio de questões e indagações, torna-se o estilo de escrita para este texto qualitativo-interpretativo.

\section{Educação Superior e a Política de Formação de Professores}

No Brasil, a política que orienta as ações voltadas para a formação de professores vinculados ao Ensino Superior é demasiadamente tímida (SOARES; CUNHA, 2010). Enquanto algumas evidências corroboram com essa afirmação, outras apontam para a urgência de se enfrentar os desafios intrínsecos à formação docente.

Na sequência, há exemplos que evidenciam o que se deseja reforçar: o descompasso existente entre a referida política e a importância que a Educação assume em sociedades intensivas em conhecimento, submetidas à lógica imposta pela economia do conhecimento (ROBERTSON, 2009); as exigências de novas competências docentes frente à revolução da tecnologia da informação e a velocidade que ela imprime à geração e difusão do conhecimento (CASTELLS, 1999); a necessidade de promover transformações na formação de professores e estudantes resultantes da crise dos paradigmas científico e pedagógico (PEREIRA, 2002); a crescente exigência de qualificação de jovens e adultos no contexto das modificações que se processam no universo do trabalho (POCHMANN, 2005); as exigências de um sistema de educação superior que tem ganhado em complexidade devido à sua rápida expansão e diversificação; a incorporação de crescente número de profissionais sem formação pedagógica ou experiência docente no Ensino Superior; a emergência de políticas de inclusão no Ensino Superior e a repercussão sobre a heterogeneidade dos estudantes e professores (SPELLER; ROBL; MENEGHEL, 2012); as transformações observadas nas funções esperadas das Instituições de Educação Superior (IES) e respectivos professores (ROBERTSON, 2009); a crescente percepção dos docentes acerca da necessidade de formação psicopedagógica anterior e paralela ao exercício profissional; a baixa correlação entre a formação oferecida pelos PPG, a melhoria da formação do professor e a elevação da qualidade da docência universitária; a limitada correlação observada entre formação de Pós-Graduação lato e stricto sensu e a elevação da qualidade da formação dos estudantes de Graduação (PACHANE; PEREIRA, 2004).

Qual é o aparato legal que apoia a formação de professores para educação superior? Quais são os limites dos referidos documentos? Em 1983, o CFE publicou a Resolução n ${ }^{\circ}$ 12/83 cujo conteúdo estabelece que 1/6 da carga horária dos cursos de especialização oferecidos no País seria dedicado à oferta de disciplinas de conteúdo pedagógico. Para suprir essa exigência legal, alguns curricula passaram a incluir a disciplina Metodologia do Ensino Superior. Em 1988 foi promulgada a nova Constituição Brasileira e o artigo n”. 207 dispõe que "as universidades [...] obedecerão ao princípio da indissociabilidade entre ensino, pesquisa e extensão" e isso requer crescente número de professores titulados em sala de aula.

Em 1996 foi publicada a nova LDB e ao tratar dos profissionais da Educação Superior, o conteúdo do Artigo $\mathrm{n}^{\circ}$. 66 esclarece que "a preparação para o exercício do magistério superior far-se-á em nível de pós-graduação, prioritariamente em programas de mestrado e doutorado". Em 1999, a CAPES publicou a Circular n”. 028/99/PR/CAPES e tornou o estágio de docência obrigatório para seus bolsistas. Passados quase dois anos (19/12/2000), a presidente da Câmara de Pesquisa e Pós-Graduação da CAPES - Ana Maria Fernandes estabeleceu normas a serem respeitadas na organização e realização do referido estágio entre os PPG do País.

Cumprindo o disposto no Artigo 214 da Constituição Brasileira, em 2001 foi sancionada a Lei n ${ }^{\circ}$. 10.172/2001 que aprova o PNE 2001-2010 (Lei n. 10172, 2001). Apesar de abrir os objetivos e metas se comprometendo a 
"prover, até o final da década, a oferta de Educação Superior para, pelo menos, 30\% da faixa etária de 18 a 24 anos" (p.58) e investir em programas de avaliação da qualidade, o conteúdo do documento é omisso ao tratar da formação do Professor para o ensino superior uma vez que se limita a explicitar a intenção de promover "o aumento anual do número de mestres e de doutores formados no sistema nacional de Pós-Graduação em, pelo menos, 5\%" (p.60) (BOLLMANN, 2010; MATTOS; VENCO, 2015; VALENTE; ROMANO, 2002).

Apenas em Junho de 2014 é sancionada a Lei no 13.005 que aprova o PNE 2014-2024 (Lei n. 13.005, 2014). O documento aprovado reúne 14 Artigos, pormenorizados em 20 metas estratégicas. Estas, por sua vez, são detalhadas em ações que variam em número. Entre as 20 metas estratégicas, três se referem ao Ensino Superior e reforçam a intenção de ampliar o acesso à Educação Superior pública (elevar a taxa bruta de matrícula para 50\% e a taxa líquida para 33\% da população de 18 a 24 anos, assegurada a qualidade da oferta e expansão para, pelo menos, $40 \%$ das novas matrículas em universidades públicas); elevar a qualidade do Ensino Superior pelo aumento do número de docentes mestres e doutores nos cursos oferecidos (para 75\%, sendo, do total, no mínimo, 35\% doutores); aumentar o total de matrículas nos PPG e o número de mestres (para 60.000) e doutores (para 25.000). Caberia, então, questionar em que medida mestres e doutores promovem a elevação da qualidade do Ensino Superior?

\section{Política de Formação de Professores e a Qualidade do Ensino}

Melhorar a formação dos professores equivale a melhorar a formação do estudante! No entanto, essa autoevidência remete a outras questões: essa política de Governo fortalece a formação de professores ou a formação de profissionais das mais diversas áreas de conhecimento? Considerando o currículo dos PPG, qual é o espaço reservado para a discussão de temas relacionados à Educação e ao Ensino Superior? Essa política tem colaborado para a formação de mestres ou para sedimentar a crença de que "quem sabe, automaticamente sabe ensinar" (MASETTO, 2014, p. 11)? Fortalecer a naturalização da docência não contribuiria para reforçar o processo de desvalorização social da atividade docente? Até que ponto isso representa o pano de fundo da indigesta questão você trabalha ou apenas ensina?

Estudiosos do campo asseguram que nos desenhos dos PPG existentes no País, a preparação para docência superior, quando há, restringe-se ao oferecimento da disciplina metodologia do ensino superior, que na prática não ultrapassa 60 horas de atividades (ANASTASIOU, 2003; MASETTO, 2012). Pensar nessa ação com muito otimismo equivale a acreditar que é possível formar (e não preparar - como legisla a LDB/1996) um Professor com a oferta de uma disciplina isolada, quando isso não seria admissível no caso de um piloto de avião, um auxiliar de enfermagem, tampouco para um chef de cuisine.

Sobre isso, Cunha (2000, p. 46) chama atenção para o fato de as universidades alimentarem curioso paradoxo: enquanto edificam as bases teóricas e metodológicas de uma área de conhecimento específica e própria ao exercício do magistério, criando e oferecendo cursos de Licenciatura que se comprometem a formar docentes para o Ensino Fundamental e Médio, negam a existência deste saber, quando se trata de seus próprios professores! Afinal, qual é o profissional que pode ser formado em tão pouco tempo e com tão limitadas oportunidades de leitura e reflexão sobre o campo? Caberia indagar em que medida a realização da referida disciplina tem sido suficiente para promover o desenvolvimento de conhecimentos, habilidades e atitudes típicas do magistério superior? E até que ponto essa experiência tem se revelado suficiente para superar os limites impostos por uma espécie de naturalização do exercício do magistério superior?

Dados oficiais revelam expressivo crescimento do número de mestres e doutores no País: em 2010 foram 35.965 mestres acadêmicos, 3.236 mestres profissionais e 11.210 doutores. Dois anos depois (2012) esses números cresceram para 42.780, 4.251 e 13.879, respectivamente, exercendo forte influência sobre a elevação do total de Professores titulados nas universidades brasileiras: enquanto a participação de professores titulados cresce entre as instituições privadas, sobretudo entre as universidades públicas observa-se flagrante redução do número daqueles com formação máxima de especialista (Tabela 2).

A elevação do número de mestres e doutores também exerce inegável influência sobre a criação de grupos de pesquisa cadastrados no CNPq: enquanto em 2000 eram 11.770, em 2010 o número mais que duplicou (27.523). Repercute igualmente sobre a publicação de artigos em periódicos acadêmicos: entre 2001 e 2011, o Brasil conheceu expressivo aumento no número de artigos publicados em periódicos indexados pelo Institute for Scientific Information (ISI). Com isso, o País conquistou 13 lugar no ranking mundial: em 2001 o número de artigos assinados por pesquisadores brasileiros atingiu 13.846; em 2007 foram 19.436; em 2008 saltou para 30.145; e em 2011 atingiu 49.664 artigos. Mas será que a titulação dos Professores exerce influência sobre a elevação da qualidade do ensino superior? 
Tabela 2: Formação Acadêmica dos Professores da Educação Superior (2003-2013).

\begin{tabular}{lllllll}
\multicolumn{2}{c}{ Brasil } & & \multicolumn{2}{c}{ Rede Pública } & \multicolumn{2}{c}{ Rede Privada } \\
\multicolumn{1}{c}{$\mathbf{2 0 0 3 - \mathbf { 2 0 1 3 }}$} & $\mathbf{2 0 0 3}$ & $\mathbf{2 0 1 3}$ & $\mathbf{2 0 0 3}$ & $\mathbf{2 0 1 3}$ & $\mathbf{2 0 0 3}$ & $\mathbf{2 0 1 3}$ \\
\cline { 2 - 7 } Doutor & 21,4 & 33,0 & 39,5 & 53,2 & 11,8 & 18,2 \\
Mestre & 35,1 & 39,7 & 27,3 & 29,6 & 39,3 & 47,1 \\
Até Especialista & 43,4 & 27,3 & 33,3 & 17,2 & 48,9 & 34,7 \\
\hline
\end{tabular}

Fonte: MEC/INEP/Censup (2013).

A análise dos indicadores de qualidade da Educação Superior, divulgados pelo Ministério da Educação (Fev. 2015), revela que, de forma isolada, não há correlação direta entre o desempenho dos estudantes submetidos ao Enade e a porcentagem de mestres e doutores nos cursos de Graduação analisados. Os microdados referentes a 4.319 cursos avaliados na edição 2013 do Enade permitem calcular coeficientes de Correlação Linear de Person de 0,30 entre o desempenho dos estudantes (nota geral do curso no Enade) e o percentual de professores mestres no curso e de 0,29 entre o desempenho dos estudantes e o percentual de professores doutores.

Frente ao exposto é possível assegurar que o aumento do número de mestres e doutores influiu sobre a elevação do número de grupos de pesquisa cadastrados no CNPq e de publicações em periódicos científicos indexados, mas dificilmente poderia se afirmar que influiu igualmente sobre o crescimento da qualidade e pertinência da atividade de ensino. Conclusão que merece ser problematizada na medida em que no contexto da sociedade intensiva em conhecimento, mais do que um agente capaz de produzir e transmitir dados e informações, faz-se necessário redefinir o professor pela via da aprendizagem. Assim sendo, Professor é quem sabe aprender com virtudes comprovadas e reconhecidas e quem sabe ampliar as condições que favorecem o estudante aprender (DEMO, 2001; 2011). O que faltaria nos PPGA para que a presença de mestres e doutores nos cursos de graduação contribuísse para a elevação da qualidade do ensino?

\section{Política de Formação Docente: Formação ou Preparação de Professores?}

Diferentemente da versão original, proposta pelo então senador Darcy Ribeiro, a LDB de 1996 é considerada omissa sobre a política de formação pedagógica do Professor universitário porque foi empobrecida ao ter importante trecho excluído - "acompanhados da respectiva formação didático-pedagógica, inclusive de modo a capacitar o uso das modernas tecnologias de ensino" - como é possível perceber ao comparar os Artigos abaixo descritos.

LDB / Art. 74 (versão provisória) - A preparação para o exercício do magistério superior se faz em nível de pós-graduação, em programas de mestrado e doutorado, acompanhados da respectiva formação didático-pedagógica, inclusive de modo a capacitar o uso das modernas tecnologias de ensino (PACHANE; PEREIRA, 2004, p. 2).

LDB / Art. 66 - (versão publicada) A preparação para o exercício do magistério superior far-se-á em nível de pós-graduação, prioritariamente em programas de mestrado e doutorado (Lei n. 9.394, 1996).

Além disso, chama-se atenção para o uso, em ambas versões, do termo "preparação para o exercício do magistério superior". Há muitos estudiosos de expressão mundial que contribuíram para a discussão do conceito de formação (bildung) (ADORNO, 2014; FICHTE, 1999; HUMBOLDT, 1997). Contudo, ao tratar da formação de docentes para o exercício do magistério superior, o conteúdo da LDB (1996) utiliza o termo preparação. Frente ao exposto, duas observações merecem destaque: enquanto formação é um conceito, preparação é apenas um termo; o que isso implica? Conceitos são portadores de significados precisos na medida em que ganham sentido no contexto de determinada construção teórica.

Diferentemente dos termos, os conceitos não têm sinônimos, consequentemente, seu uso permite que o discurso acadêmico seja universalmente compreendido. Enquanto formação pressupõe um processo, preparação 
remete a algo pontual, localizado, específico, preparar exercícios e provas, visitas técnicas, roteiros de entrevistas etc. Consequentemente, o termo preparação não se aplica ao processo de formação de uma pessoa ou de um profissional. Ao fazer uso do referido termo, consciente ou inconscientemente, os autores do documento aligeiram a política de formação docente.

Conclusões de pesquisa realizada em âmbito nacional acerca da maneira pela qual a disciplina metodologia do ensino superior é concebida e ministrada nos cursos de pós-graduação do País revelaram que, salvo exceções, ela reproduz os conteúdos privilegiados nas disciplinas pedagógicas dos curricula da Licenciatura. Além disso, assumem caráter predominantemente normativo e prescritivo, resultantes dos livros texto utilizados. Contudo, a Educação comprometida com a emancipação dos sujeitos pressupõe disciplinas formadoras e não performáticas (ADORNO, 2014).

De forma complementar, resultados de uma investigação que objetivou identificar as percepções a respeito da necessidade de formação pedagógica para o exercício da docência superior, tendo experientes professores da Universidade de São Paulo como interlocutores, apontam que a existência de uma disciplina voltada para a formação pedagógica dificilmente daria conta de responder à variedade de necessidades que cada curso e Professor apresentam. Assim sendo, não faltaram professores refratários à introdução de uma disciplina dessa natureza no âmbito da pós-graduação. Se isoladamente uma ou duas disciplinas não dão conta das exigências presentes na formação de um Professor, quais seriam as possibilidades de os PPG contribuírem para a formação de Mestres?

\section{Formação Docente e o Diálogo entre Pesquisa e Ensino}

Em 1990, uma pesquisa sobre ambientes educacionais capazes de favorecer ou dificultar inovações pedagógicas, concluiu que quando existe uma política de promoção da carreira profissional que valorize o exercício da pesquisa e a atividade de ensino, isso funciona como elemento facilitador da inovação pedagógica (BÉCHARD; BÉDARD, 2009). No entanto, quando a cultura institucional valoriza a pesquisa em detrimento do ensino, ela funciona como um fator inibidor. Apesar de a Carta de 1988 reconhecer a indissociabilidade entre ensino, pesquisa e extensão como traço característico da universidade, observa-se que, na prática, essas atividades foram fatiadas. Enquanto os cursos de Graduação e Pós-Graduação lato sensu trabalham o conhecimento como produto, os PPG trabalham o conhecimento como processo; o que isso significa? Que tipo de consequência é capaz de engendrar?

Enquanto os cursos de Graduação e Pós-Graduação lato sensu são orientados para a atividade de ensino, limitam-se a socializar o conhecimento consagrado, seja ele de caráter técnico ou científico; os PPG, por sua vez, são orientados pela atividade de pesquisa, colaboram para o desenvolvimento de competências típicas de pesquisadores e investem na produção de conhecimento técnico e científico. Apesar de o aparato legal sinalizar estreita relação entre ensino e pesquisa, por que essa dissociação persiste? A limitada integração entre ensino e pesquisa reflete a forma como está estruturado o campo acadêmico no interior das universidades brasileiras e das complexas relações que este mantém com as áreas do conhecimento, com os órgãos de fomento à pesquisa, com o campo editorial, e com o setor produtivo (SANTOS, 2008). Mas no que se refere à formação do professor universitário, até que ponto seria importante estabelecer estreito diálogo entre pesquisa e ensino?

Não são poucos os acadêmicos que aprofundam esse debate. No Brasil, seriam exemplos disso Bernardete Gatti, Hilton Japiassu, Lucíola Licínio Santos, Marli André, Maria Isabel Cunha, Menga Lüdke, Paulo Freire, Pedro Demo, entre outros. Apesar de eles nutrirem esse debate há algum tempo, difundirem o que pensam em suas diferentes publicações, o impacto exercido na formação de professores e na prática docente é demasiadamente tímido. Centrando a reflexão desta questão no universo da Educação Superior é possível reunir pistas que ajudem a compreender porque o sistema educacional brasileiro preserva as características de uma educação predominantemente livresca.

Historicamente, cursos bem avaliados são aqueles cujo currículo é rico em conteúdo e isso justifica a existência de verdadeiro corolário de disciplinas a serem cursadas. E bons professores são aqueles que passam o conteúdo programático previsto, sem necessariamente se ater à aprendizagem. Em virtude do desequilíbrio existente entre a limitada carga horária, quando se considera a extensão dos saberes disciplinares a serem tratados, e a exigência institucional de o professor cumprir o conteúdo programático, só resta uma alternativa: scannear o conteúdo ao longo do semestre. Nesse contexto, o compromisso de o professor ensinar (aqui, sinônimo de passar/transmitir/scannear conteúdos) se sobrepõe ao compromisso de criar ambientes que favoreceçam a aprendizagem significativa. Enquanto Montaigne (1533-1592) nomeia este procedimento de educação livresca, Paulo Freire (1921-1997) se refere à educação bancária e Demo (2004) usa a expressão procedimento reprodutivo calcado no instrucionismo. 
Reduzir o ambiente educacional a transmissão de estoques de conhecimento (dados e informações), resumidos em livros-texto ou apostilas, favorece o sistema de educação superior considerar Professores sem repertório pedagógico e com poucas condições de fundamentar exercícios reflexivos acerca da prática docente, aptos a lecionar em disciplinas de um ou mais cursos. Se a educação bancária, o instrucionismo ou o ensino livresco contribuem pouco para a formação consistente dos discentes, se são consideradas estratégias de ensino cansativas, desinteressantes e pouco consequentes quando se leva em conta a democratização do acesso a infinidade de dados e informações disponíveis, por que sobrevivem no tempo, de forma tão extensiva?

Porque ultrapassá-lo pressupõe verdadeira revolução no interior das instituições de educação superior na medida em que requer a reestruturação do projeto pedagógico do curso, particularmente o redesenho da matriz curricular na direção de expressiva redução de conteúdos e do fortalecimento de currículos mais integrados e transversais; profunda e significativa alteração na formação de Professores e nos critérios de seleção docente; exponencial ampliação/diversificação dos espaços de aprendizagem, tanto físicos quanto virtuais; familiarização de estudantes e professores com os princípios que sustentam as metodologias ativas etc. E como todo processo que envolve mudança de cultura exige tempo, aqui não existe exceção porque requer a desconstrução e a reconstrução de novos modelos mentais (DEMO, 1991; 2009; 2011).

\section{Metodologias Ativas e o Diálogo entre Pesquisa e Ensino}

Quais são os princípios estruturantes das metodologias ativas? Haveria alguma relação entre eles e a indissociabilidade entre pesquisa e ensino? Se há a referida relação, qual seria? Qual é a relação entre essa discussão, os PPGA e a formação de Professores? Por se tratar de metodologias ativas, elas envolvem múltiplas estratégias de ensino e aprendizagem, exemplos disso seriam o método do caso, ensino com pesquisa, aprendizagem baseada em problema, em projeto, em times, em jogos entre outros. Mas, o que elas têm em comum? Todas elas se inspiram no processo de construção do conhecimento e por isso mesmo a pesquisa é assumida como um princípio científico e educativo (DEMO, 2006; 2009).

Trata-se de metodologias de ensino que favorecem o aprender a aprender, razão pela qual estão fortemente comprometidas com o desenvolvimento da capacidade de investigação dos discentes. Compreensivelmente, elas promovem um ensino orientado pela e para aprendizagem significativa do Estudante, em oposição à aprendizagem mecânica. Pelo fato de a referida aprendizagem depender da mobilização do aprendiz para as atividades de estudo e pesquisa, ele é reconhecido como sujeito do processo de ensino e aprendizagem. Levando em conta que o conhecimento é construído e não recebido, o espaço da problematização e o exercício da dúvida ganham centralidade. Nessa trilha, alunos podem aprender bem com professores que aprendem bem (DEMO, 2011).

No universo das metodologias ativas, professores e estudantes utilizam procedimentos típicos do método científico para promover a construção, a desconstrução e a reconstrução do conhecimento a partir de questões derivadas do programa da disciplina, mas suficientemente instigantes para despertarem a curiosidade dos aprendizes. A mobilização do estudante para os estudos corresponde ao combustível da aprendizagem significativa. Elevar a pesquisa à condição de princípio científico e educativo significa torná-la cotidiana no ambiente didático, desfazendo a ideia de que a pesquisa só pode ser realizada por iniciados.

Para o êxito desta prática docente é imprescindível que o professor tenha desenvolvido competências típicas de um pesquisador (DEMO, 1996; 2011). Fica evidente que exercer a pesquisa como princípio científico e educativo requer estreito diálogo entre pesquisa e ensino. Se isso não ocorrer no curso dos Programas de PósGraduação, dificilmente o País formará Mestres, quando muito, contará com bons instrutores ou com técnicos competentes.

\section{Formação Docente e a Oferta de Disciplinas de Didática}

Coerente com o éthos acadêmico da universidade, o Artigo 66 da LDB de 1996 associa atividades de ensino e pesquisa ao determinar que a formação dos professores da Educação Superior estará prioritariamente - e não exclusivamente (PIMENTA; ANASTASIOU, 2005) - assegurada nos PPG. Contudo, historicamente, a formação de pesquisadores ganha centralidade nos PPG. Isso é evidenciado pela obrigatoriedade de os mestrandos realizarem a dissertação e de os doutorandos desenvolverem a tese, além da pressão que ambos recebem para gerar publicação. Para cumprir tais requisitos, os curricula dos cursos reforçam a formação científica com a inclusão de disciplinas e práticas voltadas para o desenvolvimento de competências de pesquisa. Essa tendência é corroborada por Fischer (2006) quando a professora assevera que apesar de os PPGA oferecerem disciplinas que promovem a formação do Pesquisador, poucos incluem disciplinas e práticas voltadas à formação do Professor.

Essa constatação é confirmada ao se levar em conta os dados relativos aos PPGA, divulgados na plataforma 
oficial da CAPES. Considerando-se os dados a partir de 2007 (um ano antes do lançamento do Pró-Administração), percebe-se que a proporção de disciplinas voltadas para o desenvolvimento de competências de um pesquisador, oferecidas pelos cursos de mestrado e doutorado em Administração, é muito superior à de disciplinas voltadas para o desenvolvimento de competências didáticas e pedagógicas. Enquanto o oferecimento destas últimas aumentou de 17 para 35 disciplinas entre 2007 e 2014, as de pesquisa foram de 188 para 343, no mesmo período (Figura 1).

Levando-se em conta o número de programas e não o de disciplinas, a assimetria permanece evidente: enquanto os 37 PPGA ofereciam disciplinas de Pesquisa em 2014, apenas 22 deles tinham em seu currículo alguma disciplina de Didática. A diferença na carga horária média dessas disciplinas também é reveladora: enquanto as disciplinas de Pesquisa tiveram uma redução correspondente a 3\% (de 44,2 horas em 2007 para 42,9 horas em 2014), o decréscimo da carga horária das disciplinas de Didática foi mais acentuado: representou 24,5\% (de 54,5 horas para 41,1 horas), no mesmo período. Considerando que grande parte dos egressos dos PPG permanece na Educação, caberia questionar se o trabalho realizado por eles irá depender exclusivamente de competências de pesquisa?

Figura 1: Evolução do Oferecimento de Disciplinas de Didática e Pesquisa - 2007 a 2014.

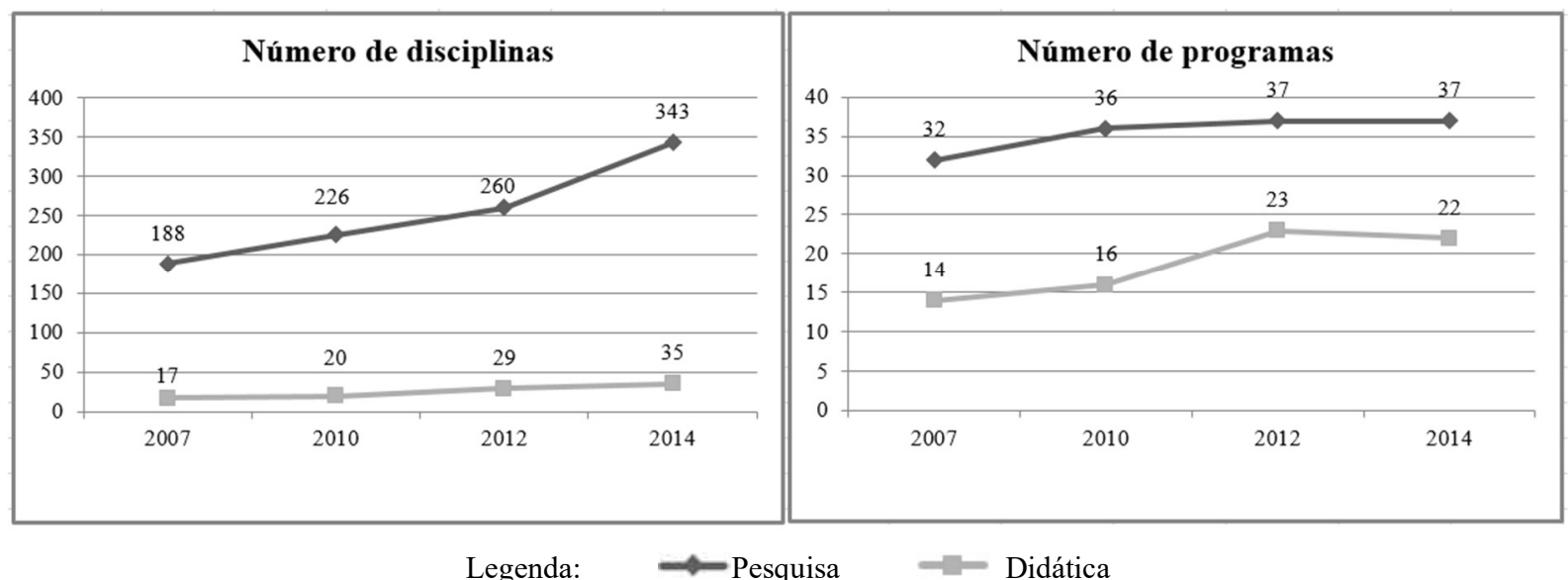

Fonte: Cadernos de Indicadores/Plataforma Sucupira/CAPES.

A LDB de 1996 classifica as IES de acordo com a organização acadêmica em universidades e nãouniversidades (centro universitário, faculdade integrada, instituto ou escola superior). $\mathrm{O}$ aspecto que diferencia universidades de não-universidades é a indissociação entre ensino, pesquisa e extensão. Na prática, exceto honrosas exceções, as instituições não-universitárias priorizam a Graduação e quando oferecem cursos PósGraduação, eles estão inscritos na modalidade lato sensu. Consequentemente, elas estão orientadas para a atividade de ensino. A concepção dos PPG, por sua vez, está orientada para a pesquisa. Assim sendo, a articulação entre pesquisa e ensino não ganha espaço em nenhuma instância do sistema de Educação Superior. Consequentemente, os egressos dos PPG estão mais familiarizados com as exigências do processo de investigação do que com as do magistério superior. Contudo, mestres e doutores terão mais chance de se vincular profissionalmente às nãouniversidades, justamente às instituições que se dedicam predominantemente à atividade de ensino.

[...] conforme o tipo de instituição de ensino superior em que o professor atua, sua docência sofrerá diferentes pressões. Se ele atua em um grupo de pesquisa em uma universidade, provavelmente sua visão de docência terá um forte condicionante de investigação. Já se ele atua numa instituição isolada [...] sua visão de docência terá um forte condicionante de ensino sem pesquisa, ou, quando muito, de ensino com pesquisa. A cultura da instituição e dai decorrente a política que ela desenvolve terão seus reflexos na docência universitária. [...] mesmo nas instituições universitárias, a afirmação de que todos os docentes tenham a sua atividade relacionada à pesquisa não é verdadeira. As instituições têm diferentes graus de desenvolvimento de pesquisa em seu interior e mesmo entre as universidades públicas (MOROSINI, 2000, p. 14 GRIFO NOSSO).

Frente ao reduzido número de disciplinas voltadas para a formação do Professor, caberia questionar se os PPG oferecem alguma atividade prática (estágio de docência, monitoria pedagógica etc.) capaz de familiarizar mestrandos e doutorandos com o ambiente educacional? 


\section{Formação Docente e a Oferta do Estágio de Docência}

Ao instituir o Estágio de Docência (1999/2000), a CAPES passa a interferir sobre a formação de professores universitários quase quatro décadas depois de criada a Pós-Graduação no País. Essa medida atinge todos os programas, mestrandos e doutorandos? Até que ponto os PPG têm condições de conceber um Estágio de Docência consequente porque capaz de contribuir para a formação pedagógica de seus bolsistas, sem perder de vista a diversidade de perfis: interesse pela docência, experiência na docência, em que tipo de instituição (universidade ou não-universidade)? Em que nível de formação (graduação ou pós-graduação)? Com qual vínculo empregatício (horista, regime de tempo parcial ou integral)? Haveria aproximação entre o estágio e a área de conhecimento em que mestrandos e doutorandos trabalham? E com o projeto de pesquisa em andamento? Tais programas dispõem de professores comprometidos com a formação pedagógica dos mestrandos e doutorandos? Até que ponto os referidos estágios são instituídos como forma de solucionar problemas circunstanciais - reduzido quadro de docentes, nas universidades públicas ou necessidade de redução de custos fixos, nas instituições particulares?

Considerando os 37 PPGA, ainda são poucos aqueles que incluem a prática em seus curricula, seja como atividade obrigatória ou eletiva. Comparado às disciplinas de Didática, o Estágio de Docência está em situação mais delicada no que diz respeito ao seu oferecimento: o número de disciplinas oferecidas entre 2007 e 2014 não passou de 20 (Figura 2). Em 2014 permaneceu abaixo até mesmo do total de disciplinas de Didática e representou pouco mais de $5 \%$ do total de disciplinas de Pesquisa (343). Ao contrário do que ocorre com Didática, cujo oferecimento tem crescido nos últimos anos, ainda que discretamente, o Estágio de Docência enfrenta um quadro de estagnação. No que diz respeito ao número de programas que oferecem disciplinas deste tipo, a diferença é ainda mais significativa: em 2014, enquanto as disciplinas de Pesquisa e Didática foram oferecidas por 37 e 22 programas, respectivamente, o oferecimento de Estágio de Docência atingiu apenas 13 deles.

Figura 2: Evolução do Oferecimento de Disciplinas de Estágio Docência e Pesquisa - 2007 a 2014.

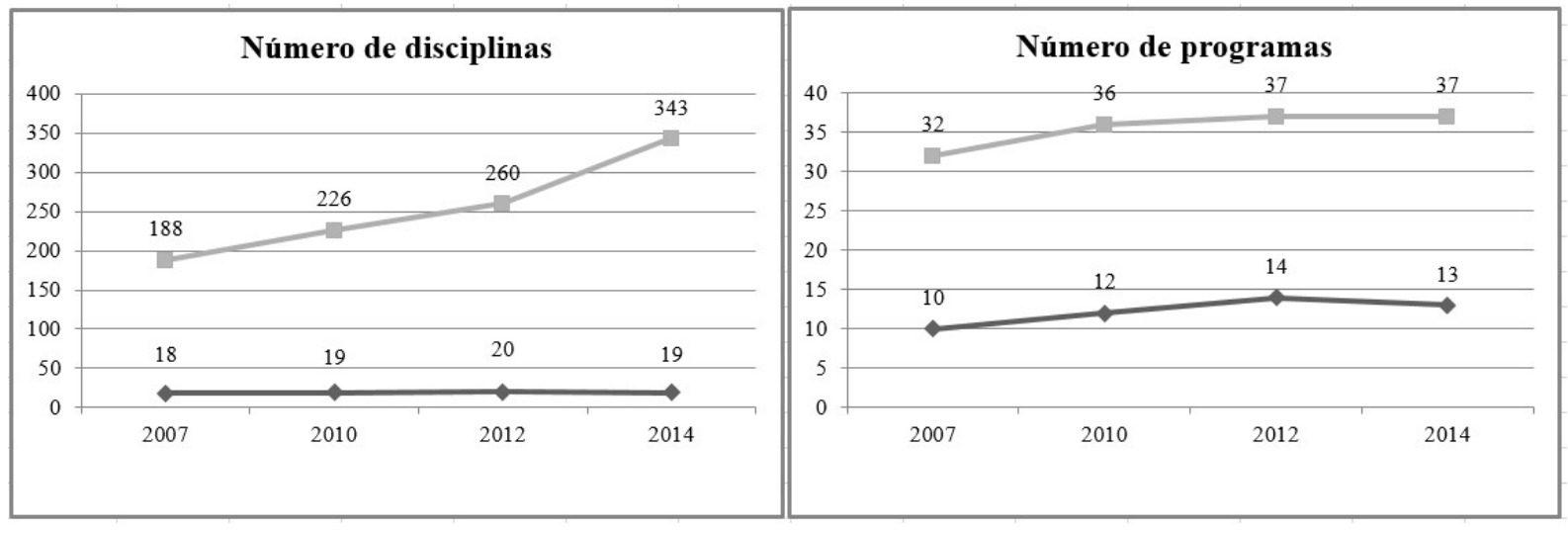

Legenda: $\quad \longrightarrow$ Pesquisa Didática

Fonte: Cadernos de Indicadores/Plataforma Sucupira/CAPES.

Também é revelador o fato de que a carga horária média das disciplinas de Estágio de Docência (30,2 horas) é inferior às de Pesquisa (42,9 horas). Esta constatação suscita estranhamento uma vez que para os bolsistas da CAPES, a realização do Estágio de Docência é obrigatória (MEC/CAPES nº 76/2010 e nº 181/2012). Se em 2014, apenas 13 PPGA ofereceram a referida disciplina, deve-se entender que os mestrandos e doutorandos dos demais Programas (24) não foram favorecidos com bolsas de estudo dessa agência? Nos limites da pesquisa documental é impossível solucionar esta questão! Levando em conta que mestrandos e doutorandos são contemplados com bolsas de estudos oferecidas pelas agências públicas nacionais e estaduais e que a elevação da qualidade da educação brasileira depende da formação cada vez mais sólida de professores, não seria de se esperar que a exemplo da CAPES, todas elas exigissem que os PPG oferecessem atividades capazes de equilibrar a formação específica, científica e pedagógica?

Tendo em vista a época em que foi criado (1999/2000), não são poucos aqueles que associaram a instituição do Estágio de Docência à carência de professores nas universidades públicas. Razão pela qual, mesmo em universidades reputadas, não é incomum que os professores orientadores transfiram para os orientados a condução de parte das atividades de ensino na Graduação. Essa distorção é tão recorrente que leva Fischer (2006) a afirmar em tom que transita da desaprovação para a denúncia. 
[...] o Professor substituto que chega a uma sala de aula sem preparação adequada na organização e no desenvolvimento do ensino não está fazendo estágio; está exercendo a docência em caráter precário, o que pode ser contraproducente e voltarse contra a formação pretendida. Igualmente [completa a Autora], substituir professores por alunos de Pós-Graduação afeta a qualidade do ensino de graduação e a formação de mestres na Pós-Graduação (FISCHER, 2006, p. 195).

Formar o professor universitário pressupõe a integração de dimensões epistemológicas, pedagógicas e políticas (BASTOS, 2007). Limitar o Estágio de Docência à observação da prática docente do professor titular da disciplina é questionável na medida em que reforça processos de reprodução. Nessa trilha, não é raro se encontrar egressos de PPG que se transformaram em perfeitos clones de seus orientadores. Reproduzem não apenas a literatura, os argumentos, os raciocínios e as ilustrações de aula, mas também os cacoetes, a entonação da voz, os vícios de linguagem etc. Na dissertação de Joaquim (2011, p. 118), sobre o Estágio de Docência, há um registro em que o entrevistado chama atenção para esse fato nos seguintes termos: "parece que o aluno de mestrado $e$ doutorado aprende a ser professor pela simples observação do comportamento de seus mestres. [...], acho que este aprendizado por imitação carrega mais vícios do que reproduz as virtudes dos professores". Por outro lado, a concepção de Estágio Docente em que mestrandos e doutorandos são promovidos a professor também é questionável. Ao assumirem turmas da Graduação sem qualquer formação pedagógica e prática docente, os resultados podem ser danosos tanto para o professor estagiário, quanto para os estudantes.

Considerando que as motivações do Edital Pró-Administração ( $\mathrm{n}^{\circ}$. 09/2008) estavam particularmente orientadas para a capacitação docente e a elevação da qualidade de ensino na área, caberia questionar em que medida os resultados dos projetos aprovados influíram sobre a formação de professores. Dados extraídos dos Cadernos de Indicadores e da Plataforma Sucupira revelam que a recorrência de disciplinas de Didática, sobretudo de Estágio de Docência, é discretamente maior entre os Programas participantes do Pró-Administração (Tabela 3). $\mathrm{O}$ fato de essa diferença ser significativa em 2007 pode sinalizar que os Programas com projetos selecionados poderiam estar sensibilizados para a necessidade de contribuírem com a formação docente e identificaram no Edital uma oportunidade para intensificar o que vinham realizando. Ainda que iniciativas como esta sejam positivas, observa-se que não foram suficientes para alterar a assimetria estrutural existente nos PPG entre a formação para a pesquisa e para a docência.

Tabela 3: Evolução do Oferecimento de Disciplinas de Didática, Estágio Docência e Pesquisa, por Participação no Pró-

\begin{tabular}{|c|c|c|c|c|c|c|c|c|}
\hline & \multicolumn{4}{|c|}{$\begin{array}{c}\text { Com Pró-Administração } \\
\text { (15 IES) }\end{array}$} & \multicolumn{4}{|c|}{$\begin{array}{c}\text { Sem Pró-Administração } \\
\text { (22 IES) }\end{array}$} \\
\hline & 2007 & 2010 & 2012 & 2014 & 2007 & 2010 & 2012 & 2014 \\
\hline Didática & 8 & 10 & 10 & 11 & 7 & 8 & 14 & 16 \\
\hline Estágio de Docência & 15 & 13 & 13 & 12 & 3 & 6 & 7 & 7 \\
\hline Pesquisa & 76 & 86 & 98 & 119 & 85 & 113 & 132 & 188 \\
\hline
\end{tabular}

Fonte: Cadernos de Indicadores/Plataforma Sucupira/CAPES.

Não é sem razão de ser que Fischer (2006) insiste em afirmar que os PPG estão pouco comprometidos com a formação do professor universitário. Por um lado, eles não sabem como fazer isso, por outro, reagem ao fato de as ações de formação docente ainda não serem consideradas prioritárias pelas instâncias reguladoras (CAPES). Afinal, a avaliação da produtividade dos PPG está fortemente associada à publicação de textos acadêmicos e muito secundariamente à participação em atividades que envolvem ensino e aprendizagem. Reiterando o histórico prestígio conferido à pesquisa, o desprestígio da docência, e a dissociação entre pesquisa e ensino.

Essa desimportância atribuída à formação de professores universitários leva pesquisadores do campo (ANASTASIOU, 2003; CUNHA, 1997; MASETTO, 2012) a assegurar que historicamente a estrutura organizativa da Educação Superior do País privilegia o domínio de conhecimentos especializados e o acúmulo de experiências profissionais como pré-requisitos para o exercício do magistério superior. Nesse contexto, compreende-se o processo de naturalização da docência refletido nos resultados de pesquisas que aprofundaram a formação do professor universitário. Tais resultados revelam que a sua história como estudante representa o fator que mais 
influencia a construção de sua prática docente.

Nas palavras de Cunha (1997, p. 81), "para além das teorias pedagógicas que ele eventualmente aprende, o que marca o seu comportamento em sala de aula são as práticas utilizadas pelos seus antigos professores". Compreensivelmente, mesmo submetidos a rigoroso processo seletivo, ao ingressar na USP, os professores que participaram da pesquisa conduzida por Chamlian (2003) não se consideravam capacitados para o exercício da docência. E, visando ultrapassarem a insegurança inicial, alguns procuraram imitar os professores que admiravam - reação que Cunha (1996) nomeia de ciclo da reprodução - alguns foram instruídos pelos seus orientadores ou colegas, alguns investiram na realização de cursos extracurriculares, e outros se iniciaram como docentes voluntários (monitores) ou colaboradores em aulas práticas ou seminários (auxiliares de ensino) (CHAMLIAN, 2003).

Apesar da experiência docente acumulada pela maioria, não foram poucos aqueles que se disseram insatisfeitos com o processo e os resultados de sua prática docente e manifestaram interesse de aperfeiçoar a sua atuação na docência superior. Resultados que permitem se questionar a concepção linear de formação de professores. E, ao mesmo tempo, reconhecer a importância da reflexão na construção do conhecimento profissional, tal como advogam diversos autores, afinal, não é possível ensinar sem aprender (FLEURI, 2009; VASCONCELLOS; DE OLIVEIRA, 2011).

\section{Considerações Finais}

Frente ao exposto, questiona-se: cabe a quem educar os professores para a docência superior? Que concepção de educação merece ser priorizada e por quê? Enquanto a questão não é encarada como prioritária pela política educacional, esta responsabilidade tem recaído, no plano individual, sobre cada professor; no plano institucional, sobre algumas IES, sensíveis à necessidade de investir na formação de seu corpo docente - até por uma questão de sobrevivência frente ao competitivo mercado educacional, à crescente complexidade do ambiente educacional, e à emergência do Estado avaliativo. Ou seja, professores e estabelecimentos de educação superior, conscientes dos desafios colocados por uma sociedade cada vez mais insatisfeita com a qualidade da educação formal oferecida, investem os esforços possíveis na realização de atividades que promovam a educação continuada e a formação pedagógica dos docentes.

Constata-se, portanto, que a formação de docentes para a educação superior ocorre de forma irregular (no sentido de não linear), ao longo de toda a vida acadêmica (ADORNO, 2014) e profissional (FREIRE, 2001). A análise dos dados oriundos das plataformas da CAPES revelam que a formação de professores nas instituições com PPGA ainda é tímida e intermitente, a despeito de ter apresentado algum avanço nos últimos anos.

Contudo, a discussão aqui empreendida trata apenas da cobertura da formação docente (em termos de oferta de disciplinas) e não entra no mérito de sua qualidade, como realizado no trabalho de Cruz e André (2014), o que consiste na outra face dessa discussão. Se, historicamente, a formação de pesquisadores tem centralidade nos PPG em detrimento da formação de professores, qualquer investimento na ampliação desta última sem a preocupação com critérios mínimos de qualidade está fadado a ser estéril ou até mesmo prejudicial à docência superior.

Portanto, longe de discutir de forma exegética os desafios aqui retratados, este texto se constitui em uma contribuição para ampliar o debate da formação docente nos PPGA, centrada menos em respostas e mais na proposição de perguntas frente ao cenário que ora se apresenta.

\section{Referências}

ADORNO, T. W. Educação e emancipação. 4.ed. Rio de Janeiro: Paz e Terra, 2014.

ANASTASIOU, L. D. G. C. Ensinar, aprender e apreender processos de ensinagem. In: ANASTASIOU, L. D. G. C. e (ORGS.), L. P. A. (Ed.). Processos de ensinagem na universidade. Joinville, 2003.

BASTOS, C. C. B. C. Docência, pós-graduação e a melhoria do ensino na universidade: uma relação necessária.

Educere et Educare, v. 2, n. 4, p. 103-112, jul./dez 2007.

BÉCHARD, J.-P.; BÉDARD, D. Quand l'innovation pédagogique s'insère dans le curriculum. In: BÉCHARD, J.P. e BÉDARD, D. (Ed.). Inover dans l'enseignement supérieur. Paris: PUF, 2009. 
BOLlmanN, M. D. G. N. Revendo o Plano Nacional de Educação: proposta da sociedade brasileira. Educ. Soc., Campinas, v. 31, n. 112, p. 657-676, jul./set. 2010.

CASTELLS, M. A sociedade em rede. 3.ed. São Paulo: Paz e Terra, 1999.

CHAMLIAN, H. C. Docência na universidade: professores inovadores na USP. Cadernos de Pesquisa, São Paulo, v. 1, n. 118, p. 41-64, 2003.

CONSTITUIÇÃO DO BRASIL. $\quad 1988 . \quad$ Disponível em: http://www.planalto.gov.br/ccivil_03/constituicao/constituicao.htm >. Acesso em: 12 mar. 2015.

CRUZ, G. B. D.; ANDRÉ, M. E. D. A. D. Ensino de didática: um estudo sobre concepções e práticas de professores formadores. Educação em Revista, v. 30, n. 4, p. 181-203, 2014.

CUNHA, M. I. D. Ensino com pesquisa a pr-tica do professor universit·rio. Cadernos de Pesquisa: Revista de Estudos e Pesquisas em Educação, Fundação Carlos Chagas, São Paulo, n. 97, p. 31-46, maio 1996.

Aula universitária: inovação e pesquisa. In: LEITE, D. e MIROSHI, M. (Ed.). Universidade futuramente: produção do ensino e renovação. Campinas: Papirus, 1997.

. Ensino como mediação da formação do professor universitário. In: MOROSINI, M. C. (Ed.). Professor do ensino superior: identidade, docência e formação. Brasília: INEP/MEC, 2000. p.45-51.

DEMO, P. Pesquisa: princípios científico e educativo. São Paulo: Cortez \& Autores Associados, 1991.

. Educar pela pesquisa. Campinas: Editora Autores Associados, 1996. 2001 .

. Educação e Conhecimento: relação necessária, insuficiente e controversa. 2.ed. Petrópolis: Vozes,

. Aula não é necessariamente Aprendizagem. Ensaio - Avaliação e Políticas Públicas em Educação, CESGRANRIO, Rio de Janeiro, v. 12/44, p. 669-695, 2004.

. Pesquisa: princípio científico e educativo. 12.ed. São Paulo: Cortez, 2006.

Aprendizagens e novas tecnologias. Revista Brasileira de Docência, Ensino e Pesquisa em Educação Física, v. 1, p. 53-75, ago. 2009.

Outro Professor: alunos podem aprender bem com professores que aprendem bem. Jundiaí: Paco Editorial, 2011.

FICHTE, J. G. Por uma universidade orgânica. Rio de Janeiro: EdUERJ, 1999.

FISCHER, T. Uma Luz Sobre as Práticas Docentes na PósGraduaçăo: a Pesquisa Sobre Ensino e Aprendizagem em Administraçăo. RAC, v. 10, n. 4, p. 193-197, out./dez. 2006.

FLEURI, R. M. Educação intercultural e a irrupção das diferenças. In: PEREIRA, M. Z. D. C. e ET AL. (Ed.). Globalização, interculturalidade e currículo na cena escolar. Campinas: Alínea, 2009.

FREIRE, A. M. Concepções orientadoras do processo de aprendizagem do ensino nos estágios pedagógicos. Colóquio Modelos e Práticas de Formação Inicial de Professores, Faculdade de Psicologia e de Ciências da Educação, 2001. 
HUMBOLDT, W. V. Sobre a organização interna e externa das instituições científicas superiores em Berlim. In: KRETSCHMER, J. e ROCHA, J. C. D. C. (Ed.). Um mundo sem universidades? Rio de Janeiro: EdUERJ, 1997.

JOAQUIM, N. D. F. Desafios da formação docente: estágio docência e a prática de ensino em Administração. 2011. 198 f. Programa de Pós-graduação em Administração, Universidade Federal de Lavras - UFLA, Lavras.

Lei $\mathrm{n}^{\circ}$ 9.394, de 20 de Dezembro de 1996. Estabelece as diretrizes e bases da educação nacional. 1996. Disponível em: < http://www.planalto.gov.br/ccivil_03/leis/19394.htm >. Acesso em: 11 fev. 2015.

Lei $\mathrm{n}^{\circ}$ 10.172, de 9 de Janeiro de 2001. Aprova o Plano Nacional de Educação. 2001. Disponível em: < http://www.planalto.gov.br/ccivil_03/leis/leis_2001/110172.htm >. Acesso em: 12 mar. 2015.

Lei $n^{\circ}$ 13.005/2014, de 26 de Junho de 2014. Plano Nacional de Educação - PNE. 2014. Disponível em: < http://fne.mec.gov.br/images/doc/LeiPNE.pdf >. Acesso em: 12 mar. 2015.

LIMA, M. C.; SILVA, C. C. D. S. A (in)competência diplomada. In: CASAQUI, V. e ET AL. (Ed.). Trabalhar em publicidade: história, formação profissional, consumo e imaginário. São Paulo: Atlas, 2011.

Professores como designers educacionais. XXXVIII Encontro da Anpad, p. 1-16, 13 a 17 de set. 2014.

LIPOVETSKY, G. L’ère du vide: essais sur l'individualisme contemporain. Paris: Éditions Gallimard, 1993.

MASETTO, M. T. Competência pedagógica do professor universitário. 3.ed. São Paulo: Summus, 2012.

. Docência na universidade. Edição Digital. Campinas: Papirus 2014.

MATTOS, R.; VENCO, S. Sistema Nacional de Educação e Plano Nacional de Educação: significado, controvérsias e perspectivas. Caderno Cedes, v. 35, n. 97, p. 611-615, 2015.

MEC/INEP. Enade: relatório 2013. 2014. Disponível em: < http://portal.inep.gov.br/enade/relatorio-sintese2013 >. Acesso em: 12 mar. 2015.

MOROSINI, M. C. Docência universitária e os desafios da realidade educacional. In: MOROSINI, M. C. (Ed.). Professor do ensino superior: identidade, docência e formação. Brasília: INEP, 2000. p.11-33.

PACHANE, G. G.; PEREIRA, E. M. D. A. A importância da formação didático-pedagógica e a construção de um novo perfil para docentes universitários. Revista Iberoamericana de Educación, n. 33/34, 2004.

PEREIRA, R. A. A ciência moderna, a crise dos paradigmas e sua relação com a escola e com o currículo. 2002. 159 f. Dissertação apresentada ao Programa de Pós-graduação em Educação, Mestrado em Educação, Pontifícia Universidade Católica de Minas Gerais, Belo Horizonte.

PIMENTA, S. G.; ANASTASIOU, L. D. G. C. Docência no ensino superior. 2.ed. São Paulo: Cortez, 2005.

POCHMANN, M. O emprego na globalização. 3.ed. São Paulo: Boitempo, 2005.

PRASAD, P. Crafting qualitative research: working in the postpositivist traditions. New York: ME Sharpe, 2005. 
ROBERTSON, S. L. Professoras são importantes, não? Posicionando as professoras e seu trabalho na economia do conhecimento global. In: PEREIRA, M. Z. D. C. e ET AL. (Ed.). Globalização, interculturalidade e currículo na cena escolar. Campinas: Alínea, 2009.

SANTOS, F. L. C. P. Dilemas e perspectivas na relação entre ensino e pesquisa. In: ANDRÉ, M. (Ed.). O papel da pesquisa na formação e na prática dos professores. 8.ed. Campinas: Papirus, 2008.

SOARES, S. R.; CUNHA, M. I. D. Formação do professor: a docência universitária em busca de legitimidade. EDUFBA, 2010.

SPELLER, P.; ROBL, F.; MENEGHEL, S. M. O. Desafios e perspectivas da educação superior brasileira para a próxima década. Brasília: UNESCO/CNE/MEC, 2012. 164 p.

STAKE, R. E. A arte da investigação com estudos de caso. 4.ed. Lisboa: Fundação Calouste Gulbenkian, 2016.

TARDIF, M. Saberes profissionais dos professores e conhecimentos universitários: elementos para uma epistemologia da prática profissional dos professores e suas consequências em relação à formação para o magistério. Revista Brasileira de Educação, n. 13, p. 5-24, jan./fev./abr. 2000.

TARDIF, M.; LESSARD, C. O ofício do professor: história, perspectivas e desafios internacionais. 5.ed. Petrópolis: Vozes, 2013.

VALENTE, I.; ROMANO, R. PNE: Plano Nacional de Educação ou carta de intenção? Educação e Sociedade, v. 23, n. 80 , p. $96-107,2002$.

VASCONCELLOS, M. M. M.; DE OLIVEIRA, C. C. Docência na universidade: compromisso profissional e qualidade de ensino na graduação. Educação (UFSM), v. 36, n. 2, p. 219-234, 2011. 